
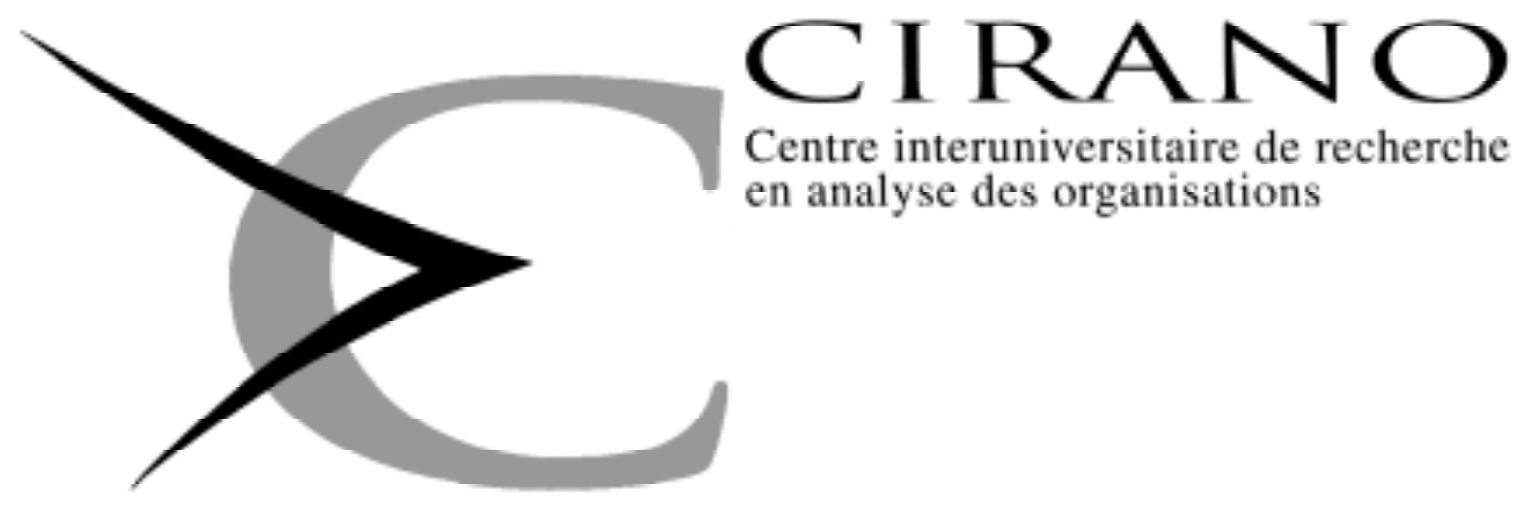
Centre interuniversitaire de recherche en analyse des organisations

Série Scientifique

Scientific Series

$\mathbf{N}^{0}$ 95s-8

AN EMPIRICAL ANALYSIS OF THE CANADIAN BUDGET PROCESS

Bryan Campbell, Eric Ghysels 


\section{CIRANO}

Le CIRANO est une corporation privée à but non lucratif constituée en vertu de la Loi des compagnies du Québec. Le financement de son infrastructure et de ses activités de recherche provient des cotisations de ses organisations-membres, d'une subvention d'infrastructure du ministère de l'Industrie, du Commerce, de la Science et de la Technologie, de même que des subventions et mandats obtenus par ses équipes de recherche. La Série Scientifique est la réalisation d'une des missions que s'est données le CIRANO, soit de développer l'analyse scientifique des organisations et des comportements stratégiques.

CIRANO is a private non-profit organization incorporated under the Québec Companies Act. Its infrastructure and research activities are funded through fees paid by member organizations, an infrastructure grant from the Ministere de l'Industrie, du Commerce, de la Science et de la Technologie, and grants and research mandates obtained by its research teams. The Scientific Series fulfils one of the missions of CIRANO: to develop the scientific analysis of organizations and strategic behaviour.

\section{Les organisations-partenaires / The Partner Organizations}

-Ministère de 1'Industrie, du Commerce, de la Science et de la Technologie.

- École des Hautes Études Commerciales.

- École Polytechnique.

- Université de Montréal.

- Université Laval.

- McGill University.

- Université du Québec à Montréal.

-Bell Québec.

- La Caisse de dépôt et de placement du Québec.

-Hydro-Québec.

-Banque Laurentienne du Canada.

-Fédération des caisses populaires de Montréal et de 1'Ouest-du-Québec.

-Téléglobe Canada.

-Société d'électrolyse et de chimie Alcan Ltée.

Ce document est publié dans l'intention de rendre accessible les résultats préliminaires de la recherche effectuée au CIRANO, afin de susciter des échanges et des suggestions. Les idées et les opinions émises sont sous l'unique responsabilité des auteurs, et ne représentent pas nécessairement les positions du CIRANO ou de ses partenaires.

This paper presents preliminary research carried out at CIRANO and aims to encourage discussion and comment. The observations and viewpoints expressed are the sole responsibility of the authors. They do not necessarily represent positions of CIRANO or its partners.

ISSN 1198-8177 


\title{
An Empirical Analysis of the Canadian Budget Process ${ }^{\star}$
}

\author{
Bryan Campbell $t^{\dagger}$ Eric Ghysels
}

\begin{abstract}
Résumé
This paper provides a statistical analysis of the forecasts of significant number of expenditure and revenue components of the Federal budget provided each year by the Department of Finance. The sample available for such an investigation is limited and we describe an easily-applied nonparametric testing methodology which is more appropriate than the usual regression-based approach in small samples. The reliability and relative power of the various nonparametric tests are illustrated in a series of simulations. Applying these tests to the fiscal forecasts, we find that there is little cause to be concerned with the forecast performance of the Department of Finance over the last seventeen years.

Dans cette étude nous examinons les erreurs de prévisions pour les comptes de dépenses et recettes du budget canadien. Nous appliquons des méthodes non-paramétriques à cause des petites tailles d'échantillons. Nous trouvons peu d'erreurs systématiques dans les prévisions budgétaires.
\end{abstract}

Keywords: budget forecast, nonparametric methods

Mots-clés : prévisions budgétaires, méthodes non-paramétriques

JEL: C12, C13, C22

\begin{abstract}
All correspondence should be addressed to the authors at the Centre de recherche et développement en économique(C.R.D.E.), Université de Montréal, C.P.6128 Succursale Centre-Ville, Montréal (Québec) CANADA H3C 3J7. The first author acknowledges the financial support of Concordia's FRPD and of the F.C.A.R. of Québec. The second author acknowledges the financial support of the F.C.A.R. and the Social Sciences and Humanities Research Council of Canada. The authors are grateful to Jean-Marie Dufour, Gordon Fisher, John Galbraith and Douglas Willson as well as seminar participants at UQAM for helpful discussions and comments. We also appreciate the help and technical support regarding the Canadian forecasting process given by the Fiscal Policy Division of the Department of Finance, in particular the insight and patience extended by Richard Davis.
\end{abstract}

$\dagger$ Department of Economics, Concordia University and Centre de recherche et développement en économique (C.R.D.E.), Université de Montréal.

${ }^{\ddagger}$ Centre de recherche et développement en économique (C.R.D.E.), Université de Montréal and CIRANO. 


\section{Introduction}

The announcement in the spring of 1994 that the Federal budget was not $\$ 35$ billion as predicted the previous fall during the election camp aign but a forbidding $\$ 45$ billion has focused attention on the reliability of fiscal forecasts produced by the Department of Finance which form the basis of the Federal Government's budgetary predictions. The political and strategic context of this revelation aside, two more general issues come immediately to mind. With what frequency have forecast errors of this magnitude occurred in the past? What was the provenance of the error: did the error originate from the expenditure or from the revenue side of the budget, and which specific budgetary forecast components contributed most to the error?

These concerns suggest that a statistical study of the specific fiscal forecasts used in the budgetary process both on the expenditure and revenue sides would be a relevant first step in the assessment of the Federal budgetary process. Whereas there is a considerable American literature on the reliability of government forecasts [see for example Shkurti and Winefordner (1989), Gentry (1989), Feenberg et al. (1989) and Plesko (1988)], there is has been surprisingly little work addressing the forecast performance of the Department of Finance in the Canadian budgetary context. A first step was taken by David and Ghysels (1989), but their focus was on forecasts of expenditure and revenue aggregates. In this paper, we are concerned as well with the specific components of forecast expenditures such as income security or debt servicing, and of revenues such income tax or excise tax receipts. Our aim is to assess the fiscal performance of the Department of Finance involving the key components of the budget over as a long a time horizon as the coherence of the series considered can be maintained. The analysis pursues the traditional issues: are budget projections systematically biased or not? Are any of the budgetary components prone to bias? Is there any evidence that past errors are overlooked in budget forecasts? Could other information in the form of important macroeconomic aggregates have improved forecast performance?

The data available to address these issues is limited. As will be seen, it is difficult to extend the analysis prior to 1976 , a limitation which imposes a small sample for statistical inference. Our position with regard to the appropriate statistical methodology to adopt is that regression-based procedures may be misleading in this context. The second contribution of this paper is to present a nonparametric methodology which incorporates exact tests for evaluating the unbiasedness and efficiency of forecasts, and to give some sense of the performance of these tests relative to the regression-based procedures in a series of simulation exercises. The theoretical basis for these tests have been established in Dufour (1981), Campbell and Dufour $(1991,1994)$ and have been applied in a forecasting study by Campbell and 
Ghysels (1994) to U. S. federal government forecasts. The tests have good finite sample properties, are robust against departures from assumptions such as normality and homoskedasticity and, as will be indicated, display good power relative to regression-based procedures even in circumstances favourable to these traditional procedures. It should be emphasized that the nonparametric approach is straightforward to apply and is of potential interest in many other applications.

The paper is organized as follows. The second section of the paper introduces the tests to be used in the applied work and through simulation studies contrasts the performance of the nonparametric approach with that obtained with the more usual regression methods for a sample comparable in size to the sample of forecasts considered in the paper. The third section discusses the Canadian budget process and introduces the twelve series to be investigated in the subsequent statistical analysis. The empirical work is presented in the fourth section. Here the nonparametric results are compared with regression-based results. Some conclusions are offered in the final section of the paper.

\section{A Nonparametric Methodology for Assessing Forecast Performance}

Over the last three decades a regression methodology has been developed to test various implications of the rational expectations hypothesis; this material is surveyed for instance in Pesaran (1987). In the particular context where expectations are observable or generated by some forecasting procedure, one has been interested in testing whether the expectation is an unbiased predictor of the realized value and whether the forecast efficiently exploits all information available to the forecaster. More precisely, let the one-period forecast error be $\left.\left(\mathrm{Y}_{\mathrm{t}}{ }^{-} \cdot\right)^{-}\right)$, with . denoting the expectation or forecast of the variable $Y_{t}$ made at time $t-j$. The claim that expectations are unbiased can be assessed by considering the regression of the error on a constant. Broader orthogonality or conditional independence claims that forecast errors are uncorrelated with the entire set of information that is costlessly available to the forecaster may be readily tested via regressions of the error on relevant past information. This regression-based testing methodology has been widely used; for representative examples see McNees (1978) and Friedman (1980) and, in the context of studies of government forecasts, Plesko (1988), David and Ghysels (1989), and Gentry (1989).

However convenient it is to apply the methodology, the results must be interpreted with considerable caution. On the one hand, deviations from the assumption that the forecast errors are normally distributed with constant variance 
throughout the sample may compromise the efficiency of the regression statistics, particularly in small samples. Tests for bias, for example, may have little power in the presence of outliers. By contrast, as illustrated in a simulation study by Mankiw and Shapiro (1986), regression procedures used to test the efficiency of forecasts may reject too often when disturbances affecting the magnitude of the forecast error are themselves correlated with future values of the regressors. Moreover, it should be emphasized that such departures from standard assumptions such as heteroskedasticity and feedback are entirely consistent with the rationality hypothesis.

Against this backdrop, we now describe a classical finite-sample nonparametric testing methodology to assess the unbiasedness and efficiency of forecasts. The test statistics considered are based on signs. These are the only statistics which can produce valid tests about a median under sufficiently general distribution assumptions; this point is emphasized by Dufour and Hallin (1991), and for a general discussion see Pratt and Gibbons (1981, pp. 233-234). The sign-based testing procedures introduced below are known to be robust to problems of nonnormality and heteroskedasticity, and are valid under conditions of feedback including the paradigm considered by Mankiw and Shapiro (1986). Moreover, the power of these tests can be considerably superior to parametric procedures in such situations. These issues are discussed in Campbell and Dufour (1991, 1994). A related feature of nonparametric testing procedures which may not be widely appreciated is that, relative to regressions tests applied in situations favourable to parametric procedures, the power lost in applying nonparametric tests is not particularly pronounced; a more thorough discussion of relative efficiency can be found in Hettmansperger (1984). This point will be illustrated in the simulation studies that are presented in this section. Finally, at the outset we should mention that the nonparametric approach focuses on the median of the forecast error rather than the mean. It is clear that for symmetric distributions with finite mean, median-unbiasedness and mean-unbiasedness are equivalent. The issue of whether one should test median-unbiasedness or meanunbiasedness in the situation of asymmetric disturbances is certainly debatable. Whatever one's position on this issue, the rational expectations hypothesis does entail median-unbiasedness when the mean absolute forecast error is minimized rather than mean square forecast error.

To parallel the regression-based methodology in forecast evaluation, we introduce in turn sign and signed rank tests for unbiasedness of forecasts and for the orthogonality of forecast errors both to past forecast errors and to available macroeconomic information. The performance of the nonparametric statistics relative to the analogous regression procedures are investigated via simulation studies as the tests are introduced. These results are presented using the graphical methods described in Davidson and Mackinnon (1994). 
Let the one-period forecast errors be written as $\mathrm{E}_{1 \mathrm{t}}=\ldots$. . . Let also $u(z)=1$ if $z \geq 0$ and $u(z)=0$ otherwise; the role of the function $u(\cdot)$ is simply to indicate whether the forecast error is positive or negative. To test the unbiasedness of forecast errors, consider first the statistics:

$$
\mathrm{S}_{1}=\sum_{\mathrm{t}=1}^{\mathrm{T}} \mathrm{u}\left(\mathrm{E}_{1 \mathrm{t}}\right) \quad \text { and } \quad \mathrm{W}_{1}=\sum_{\mathrm{t}=1}^{\mathrm{T}} \mathrm{u}\left(\mathrm{E}_{1 \mathrm{t}}\right) \mathrm{R}_{1 \mathrm{t}}^{+},
$$

with $\mathrm{R}_{1 \mathrm{t}}{ }^{+}$the rank of $\left|\mathrm{E}_{1 \mathrm{t}}\right|$, when $\left|\mathrm{E}_{11}\right|, \ldots . .,\left|\mathrm{E}_{1 \mathrm{~T}}\right|$ are placed in ascending order and $\mathrm{T}$ is the sample size. These traditional nonparametric statistics are used in tests of location in very general circumstances; see Hettmansperger (1984) for a systematic presentation. Under the general null hypothesis that the forecast errors are independent with 0 median, the sign statistic $S_{1}$ is distributed $\operatorname{Bin}(T, 0.5)$; that is, as the binomial distribution with number of trials $\mathrm{T}$ and probability of success 0.5 . Under the additional assumption that the forecast errors are symmetric about 0 , the statistic $\mathrm{W}_{1}$ has the Wilcoxon signed rank distribution (ie, like the weighted sum of $\mathrm{T}$ independent $\operatorname{Bin}(1,0.5)$ variates); for a general discussion see Lehmann (1975). The two statistics $S_{1}$ and $W_{1}$ can thus be used to test the hypothesis that the one-period forecast errors are centered at 0 . In passing it should be remarked that $W_{1}$ under the null has been tabled for sample sizes up to 50--see, for example, Wilcoxon, Katti and Wilcox (1970)-- and that the normal approximation with $\mathrm{E}\left(\mathrm{W}_{1}\right)=\mathrm{T}(\mathrm{T}+1) / 4$ and $\operatorname{Var}\left(\mathrm{W}_{1}\right)=\mathrm{T}(\mathrm{T}+1)(2 \mathrm{~T}+1) / 24$ works well even for small values of $\mathrm{T}$.

To assess the relative performance of $\mathrm{S}_{1}$ and $\mathrm{W}_{1}$ relative to the t-statistic, the usual parametric procedure to use in location tests, we considered a simulation involving 20 random draws from a distribution perhaps with non-zero center. The sample size corresponds roughly to the length of the forecast samples considered in the empirical study in the next section. For each of 5000 replications, we computed the probability values associated with each of the sign, Wilcoxon and t-statistics under the null hypothesis that the center of the distribution is 0 . Three empirical distribution functions of the probability values corresponding to the statistics are then estimated:

$$
\hat{\mathrm{F}}_{\mathrm{k}}\left(\mathrm{x}_{\mathrm{i}}\right)=\frac{1}{\mathrm{~N}} \sum_{\mathrm{j}=1}^{\mathrm{N}} \mathrm{I}\left(\mathrm{p}_{\mathrm{j}} \leq \mathrm{x}_{\mathrm{i}}\right),
$$

where $\mathrm{I}\left(\mathrm{p}_{\mathrm{j}} \leq \mathrm{x}_{\mathrm{i}}\right)$ is 1 if the argument is true and 0 otherwise, $\mathrm{N}=5000$ and for $\mathrm{k}=1$, 2,3 corresponding to the three statistics. The values $x_{i}, i=1, \ldots, m$, correspond to a grid of the $[0,1]$ interval; we follow Davidson and Mackinnon (1994) and consider $\mathrm{m}=215$ with $\mathrm{x}_{\mathrm{i}}=.001, .002, \ldots .010, .015, \ldots, .990, .991, \ldots .999$.

In this section, two types of graphs based $\hat{\mathrm{F}}_{\mathrm{k}}\left(\mathrm{x}_{\mathrm{i}}\right)$ on will be considered. The direct plot of $\hat{F}_{k}\left(x_{i}\right)$ against $x_{i}$, or what is called a P- value plot, is a measure of how 
the underlying statistics perform for various nominal sizes. If the simulated distribution is $\mathrm{N}(0,1)$, for example, then it is clear that the distributions used to compute the probability values of the three statistics are all correct and the resulting $\mathrm{P}$-value plots should be close to the $45^{\circ}$ line. On the other hand, if the simulations were based on $\mathrm{N}(0.5,1)$, the distance from the $45^{\circ}$ line in the P-value plots is an indication of the power of the test. The presentation of the empirical distribution functions $\hat{\mathrm{F}}_{\mathrm{k}}\left(\mathrm{x}_{\mathrm{i}}\right)(\mathrm{k}=1,2,3)$ within the same graph gives immediate insight into the relative power of the three underlying tests. To investigate the power of a test in situations where the true size does not correspond to the nominal size, it is more reasonable to consider a size-power curve which traces the points $\left(\hat{\mathrm{F}}_{\mathrm{k}}\left(\mathrm{x}_{\mathrm{i}}\right), \hat{\mathrm{F}}_{\mathrm{k}}^{*}\left(\mathrm{x}_{\mathrm{i}}\right)\right)$, where $\hat{\mathrm{F}}_{\mathrm{k}}(\mathrm{x})$ and $\hat{\mathrm{F}}_{\mathrm{k}}^{*}(\mathrm{x})$ are the empirical distribution functions under the null and alternative respectively. In this way, the power of the test is size corrected. Davidson and Mackinnon (1994) should be consulted for further details and an illustration.

Figure 1 presents four P-value plots to assess the relative performance of the sign, Wilcoxon and t-statistics in detecting bias for various simulated distributions when the sample size is 20 . In the case of normal disturbances with mean 0.4 , the striking message is that there is very little loss of power in using the Wilcoxon test and relatively little in applying the sign test. When the disturbances are Cauchy with nonzero median, a distribution which has fat tails, the two nonparametric procedures have equivalent power and clearly dominate the t-test. The third example considers the asymmetric chi-squared distribution with four degrees of freedom which has been centered at its median. The graphical results reveal at a glance that both the Wilcoxon and the t-statistics over reject the true null in this environment, and underscore the necessity of the symmetry assumption in applying these tests. To assess the performance of the statistics in the presence of heteroskedasticity, samples were drawn from a normal distribution with non-zero mean with unit variance for the first fifteen points and with variance 16 for the last five. Figure 1(d) reveals that the t-test has little power to detect the alternative in the presence of such a systematic break in the variance, while the two nonparametric tests perform considerably better with comparable power. In sum, the message conveyed by these pictures is clear: there are very good reasons to use the nonparametric procedures in a sample of such size with very little cost in power in the one circumstance which favours to the use of the $t$ statistic.

To test for serial correlation in the forecast errors, let $\quad=E_{1 \mathrm{t}} \mathrm{E}_{1(\mathrm{t}-\mathrm{k})}$, and consider the statistics:

$$
\mathrm{SC}_{\mathrm{k}}=\sum_{\mathrm{t}=\mathrm{k}+1}^{\mathrm{T}} \mathrm{u}\left(\mathrm{Z}_{1 \mathrm{t}}^{\mathrm{k}}\right) \quad \text { and } \quad \mathrm{WC}_{\mathrm{k}}=\sum_{\mathrm{t}=\mathrm{k}+1}^{\mathrm{T}} \mathrm{u}\left(\mathrm{Z}_{1 \mathrm{t}}^{\mathrm{k}}\right) \mathrm{R}_{2 \mathrm{t}}^{+}
$$


where $\mathrm{R}_{2 t}{ }^{+}$is the signed rank of the product $Z_{1 t}, t=1, \ldots, T$. These tests, introduced by Dufour (1981), can be interpreted as location tests: correlation between $E_{1 t}$ and $E_{1(t-k)}$ will tend to move the center of their product away from 0 . More formally, if the $\mathrm{E}_{1 \mathrm{t}}$ have 0 median and are uncorrelated at length $\mathrm{k}$, then the statistic $\mathrm{SC}_{\mathrm{k}}$ is distributed $\operatorname{Bin}(T-k, 0.5)$ and, on the additional assumption of the symmetry of the forecast errors about 0 , the $\mathrm{WC}_{\mathrm{k}}$ statistics are distributed Wilcoxon signed rank of size T-k. Again it is important to stress that the validity of tests based on $\mathrm{SC}_{\mathrm{k}}$ and $\mathrm{WC}$ is not compromised by non-normal or heteroskedastic forecast errors.

Figure 2 presents the results of simulations similar to the previous study, but in the context of first-order correlation defined by:

$$
\mathrm{E}_{1 \mathrm{t}}=\rho \mathrm{E}_{1, \mathrm{t}-1}+\epsilon_{\mathrm{t}},
$$

$\mathrm{t}=1, \ldots, \mathrm{T}$, where the disturbances $\epsilon_{\mathrm{t}}$ are either standard normal, Cauchy, or heteroskedastic. Along with the nonparametric statistics are defined as in (3), we also consider the t-statistic based on a regression without a constant term of the forecast error on its own lag. The Wilcoxon test displays credible power with regard to the tstatistic as shown in Figure 2(a) where the disturbances are normal, and completely outperforms its parametric alternative in the case of Cauchy disturbances as is evident in Figure 2(b). The unreliability of the t-statistic based on a regression without a constant where the disturbances are heteroskedastic is illustrated in Figure 2(c), which presents as well the expected empirical confirmation that the nonparametric statistics are reliable in such a context. In Figure 2(d), which is a size-power plot of the performance of the t-statistic, the sign statistic is seen to perform as well as the sizecorrected t-statistic. Clearly, the results of Figure 2 support the theme struck in the previous simulations regarding bias: there is no compelling reason to use the t-test over the sign and Wilcoxon tests.

To show that forecast errors are independent of previous information available to the forecaster, denoted $X_{t}$, we first introduce the series ${ }_{t} X^{\circ}$ which represents an attempt to center $\mathrm{X}_{\mathrm{t}}$ around 0 using only information available at time t. For one example, consider

$$
X_{t}{ }^{\mathrm{c}}=\mathrm{X}_{\mathrm{t}} \text { - median }\left(\mathrm{X}_{1}, \mathrm{X}_{2}, \ldots, \mathrm{X}_{\mathrm{t}}\right) \text {. }
$$

For one-period forecasts, the efficiency or orthogonality tests to assess whether the forecaster has made efficient use of available information represented by the series $\mathrm{X}$ up to time $t$ are based on statistics of the form $Z_{t}^{k}=E_{1 t}$ . , with $E_{1 t}$ the one-period forecast error defined in $\mathrm{A}$. and $\mathrm{k} \geq 1$. Let the sign and signed rank statistics be respectively defined as: 


$$
\mathrm{SO}_{\mathrm{k}}=\sum_{\mathrm{t}=\mathrm{k}+1}^{\mathrm{T}} \mathbf{u}\left(\mathrm{Z}_{\mathrm{t}}^{\mathrm{k}}\right) \quad \text { and } \quad \mathrm{WO}_{\mathrm{k}}=\sum_{\mathrm{t}=\mathrm{k}+1}^{\mathrm{T}} \mathbf{u}\left(\mathrm{Z}_{\mathrm{t}}^{\mathrm{k}}\right) \mathrm{R}_{1 \mathrm{t}}^{+}
$$

where $\mathrm{R}_{1 \mathrm{t}}{ }^{+}$is the signed rank of $\mathrm{E}_{1 \mathrm{t}}, \mathrm{t}=\mathrm{k}+1, \ldots, \mathrm{T}$, and $\mathrm{k} \geq 1$. Under the null that the forecast errors have median zero and are mutually independent, $\mathrm{SO}_{\mathrm{k}}$ and $\mathrm{WO}_{\mathrm{k}}$ are distributed respectively binomial and Wilcoxon sign rank of size T-k. These procedures, which have been introduced in Campbell and Dufour $(1991,1994)$, are not only robust to the presence of non-normal and/or heteroskedastic disturbances but are valid in the presence of feedback of the sort studied by Mankiw and Shapiro (1986).

Several points must be added by way of clarification. First, the nonp arametric tests check whether the location of $Z_{t}{ }^{k}$ is 0 ; a non-zero center indicates that there is some correlation between the forecast error at $t$ and past information $X_{t-k}$. Since the forecast errors may themselves be centered at 0 , it is necessary to center $X_{t}$ for each $t$ around 0 if the test is to have any power. It must be emphasized that the centering procedure should only use information available at the time of the forecast. The second observation concerns the Wilcoxon statistic: to preserve results which establish the small sample distribution, the signed ranks of the forecast errors and not of $Z_{t}^{k}$ must be used; this innovation is introduced in Campbell and Dufour (1994). Finally, the above tests are defined relative to a single fixed $\mathrm{k}$. To test efficiency for $\mathrm{k}=1,2$ and 3 , for example, it is necessary to carry out three nonparametric tests based on $Z_{\mathrm{tk}}$ corresponding to each $\mathrm{k}$ with levels $\alpha / 3$ in order to test the null with level bounded by $\alpha$. The null is rejected if one of the tests is significant.

To assess the performance of the statistics defined by (5), we consider the following variant of the model investigated by Mankiw and Shapiro (1986):

$$
\begin{aligned}
& E_{1 t}=\beta_{1}\left(X_{t-1}-\mu\right)+\epsilon_{t}, \quad t=1, \ldots, T, \\
& X_{t}=\theta_{0}+\theta_{1} X_{t-1}+\eta_{t}, \quad t=1, \ldots T,
\end{aligned}
$$

where $\mu$ is the mean of $X_{t}$. For each of the experiments, data were generated for this model by setting $\theta_{0}=0.1, \theta_{1}=0.9$, and $\eta_{\mathrm{t}}=\rho \epsilon_{\mathrm{t}}+\sqrt{1-\rho^{2}} \eta_{\mathrm{t}}{ }^{\prime}$ where $\rho=0.9$, and $\epsilon_{\mathrm{t}}$ and $\eta^{\prime}$ are independent with the same distribution either normal, Cauchy or heteroskedastic as in the previous simulations. To test whether the forecast errors $\mathrm{E}_{1 \mathrm{t}}$ are independent of past movements of $X_{t}$, it is standard procedure to apply the t-test associated with the slope coefficient of the regression model

$$
\mathrm{E}_{1 \mathrm{t}}=\alpha_{0}+\alpha_{1} \mathrm{X}_{\mathrm{t}-1}+\epsilon_{\mathrm{t}} .
$$

Finally, in defining the nonparametric statistics (5), we arbitrarily take 


$$
\mathrm{X}_{\mathrm{t}}^{\mathrm{c}}=\left(\mathrm{X}_{\mathrm{t}}-\mathrm{X}_{\mathrm{t}-1}\right)-\sum_{\mathrm{s}=1}^{\mathrm{t}}\left(\mathrm{X}_{\mathrm{s}}-\mathrm{X}_{\mathrm{s}-1}\right) / \mathrm{t},
$$

which is the centering procedure used in the empirical analysis in the following section. The results of this simulation exercise are presented in Figure 3.

Figure 3(a) underscores the finding of Mankiw and Shapiro (1986) that the t-statistic rejects too often when $\theta$ and $\rho$ are close to 1 ; as expected, the nonparametric statistics both reject at the nominal level. In Figure 3(b), a size-power analysis which corrects the over rejection of the t-statistic under the null, it is evident that both nonparametric statistics considerably outperform the size-corrected t-test with the Wilcoxon test having a slight edge in power. As in the previous simulations, Figure $3(\mathrm{c})$, which is a P-value plot, confirms the superior power performance of the nonparametric statistics relative to the t-test when the disturb ances are Cauchy. For the final simulation involving the type of heteroskedasticity previously considered, we let $\rho=0$ so that there would be no over rejection under the null if the disturbances were identically normal. But the t-statistic none the less over rejects in the presence of heteroskedasticity and we present a power-size curve in Figure 3d. For this specification, the Wilcoxon test is the most powerful with the sign test exhibiting as much power as the size-corrected t-test. It should be emphasized here that in practice it is difficult to correct as precisely for such over rejection since the relevant critical values for the correct application of the t-test depend on the sample size, the unknown type of and the unknown parameters of the model.

To summarize: nonparametric statistics based on signs and signed ranks have been introduced in (1), (3) and (5) which can be used to test for bias and efficiency under minimal distributional assumptions. These nonparametric tests will not have any size distortions as they are exact. By contrast, regression-based methods will generally not be exact unless some strong auxiliary assumptions are met. Moreover, the nonparametric tests have shown superior power properties relative to parametric tests in the simulation studies presented in this section for a sample size frequently encountered in practice; it should be added that the tenor of the simulation results is maintained when the sample size is increased to 50 and, in certain situations such as Cauchy disturbances, for much larger sample sizes as indicated in Campbell and Dufour (1994). We can only conclude that the appropriate testing methodology to adopt when assessing certain aspects of forecast performance is nonparametric based on signs and signed ranks. 


\section{The Canadian Budget Process}

The Federal Government's fiscal year begins April 1. By law, spending estimates must be tabled in the House of Commons in March. These estimates reflect the government's view of the costs of maintaining and developing existing programmes and may incorporate as well the estimated costs of whatever policy initiatives the government may have in mind. Such initiatives are generally outlined in a Budget which is presented to Parliament around this time, although the precise timing of the Budget can be determined by political exigency. The Budget document also contains the Government's specific revenue forecasts which are presented as part of a more general picture of the course of the economy in the upcoming year. In recent years, forecasts of key macroeconomic variables such as GDP growth, unemployment rate etc. are given as well. The spending estimates are now also reported in the Public Accounts which are published each year in the fall as a record of the government's fiscal position the previous year.

The Public Accounts present the realizations of the previous year's expenditures and revenues on a detailed basis. It should be emphasized that these are published some six months after the start of the new fiscal year. Given this lag, it may be argued that the information set available in framing the upcoming year's fiscal forecast does not contain the previous year's forecast errors. The Department of Finance, however, is hardly kept in suspense regarding the realizations of the different components of the budget, as information relating to programme expenditures and various tax revenues is collected on a regular (even weekly for some variables) basis. As a consequence, we do not find it unreasonable to assume that the previous year's forecast errors are known when the current forecast is determined. In this regard, forecast procedures in Canada certainly appear to be less ragged than in the U. S. where the Executive Branch presents its forecasts to Congress some nine months before the beginning of the fiscal year as an initial step in the budgetary process; for further discussion of the implications of this long lag for forecast evaluation see Campbell and Ghysels (1994).

To obtain some insight into the structure of the Canadian budget, Table 1 presents some of the big-ticket expenditure items as a percentage of total expenditures and the major revenue items as a percentage of total revenue; the deficit is given as a percentage of total revenue. The starting point for the analysis is 1976 for reasons to be discussed below. In this presentation, total expenditures are divided into Programme Expenditures and Debt Service. Income Security covers Family Allowance, Old Age Security, Guaranteed Income Supplement and Spouse's Allowance but not U.I. Benefits which is presented as a separate category. Transfers to Governments is defined here as including Fiscal Arrangements (payments to 
provinces under the BNA Act and other statutory authority), Health Insurance (including the Insured Health Services Programme and Extended Health Care Services), Education Support (containing Post-Secondary Education Payments but not including payments under the Canada Student Loans Act) and the Canada Assistance Plan. It is relatively straightforward to track spending on these items through the Public Accounts over the period indicated. The four series listed under Programme Expenditures in Table 1 account for roughly $65 \%$ of such expenditures in 1992 . The other 35\% covers other transfers to persons and governments, net expenditures by Crown corporations, and spending by departments and agencies other than National Defence which is difficult to disaggregate into interesting components which can be followed from year to year in a coherent way.

The issue of the coherence of a spending series is closely tied to the problem of the determination of the most appropriate sample size to investigate. The analysis of the U.I. accounts is an important case in point. U.I. Benefits and Contributions were off-budget items until the fiscal year 1985-86; in other words, total budgetary expenditures as reported before 1985 did not report unemployment benefits which comprise some $10 \%$ of total expenditures. Accordingly, expenditure errors before 1985 did not include errors in the estimation of U.I. payments and would be relatively lower than in subsequent years. It would be incorrect to presume that forecasts during the earlier period were more accurate. Some adjustment to the calculation of total expenditures is necessary to establish the coherence of the series. It would be natural to add the U.I. figures to the earlier spending and revenue estimates and realizations. The problem, however, is that forecasts for the U.I. accounts are not available before 1981. To extend the sample size before 1981, we were forced to exclude the Unemployment Insurance accounts from the total spending and revenue aggregate series.

Prior to 1976 the Old Age Security account was not included in the budget. Since part of tax revenues were earmarked to support the expenditures from this account, these tax receipts were not included on the revenue side of the budget. It would be natural simply to include OAS with the Income Security series before 1976 but for the problem that forecasts for these expenditures and for those revenues reserved for this account were not included as a matter of course in the budget documents of the period. We resolved this problem by fixing on 1976 as the beginning of the sample.

Defense Spending was also excluded from the Programme Expenditure series on the grounds that these estimates of spending are less a forecast than a budget constraint. The Defense Spending series, however, is included in the Total Expenditure series. 
Total Expenditure series from 1979-80 to 1983-84 (and beyond) contains realizations and estimates on a revised accounting basis. A footnote in the budget tables indicates that the forecasts were made in light of the accounting changes. It should be admitted that there is a violation of coherence in the numbers before 197980 and after, since the former are given in the old accounting basis; but as some historical analysis indicates the differences are minor [Tables 1.1.1 and 1.1.2, Public Accounts 1979-80, 1983-84 I.5 ]

To sum up: the sample considered in this paper runs from 1976 to 1992 (17 data points), except for the U.I. accounts which cover 1981 to 1992 (11 points). The expenditure series considered include Income Security (defined above), Transfers to Governments (defined above), Programme Expenditures ( excluding Defense and U.I. Benefits), U.I. Benefits and Total Expenditures (excluding U.I. Benefits). The revenue series include Income Tax, Corporate Tax, Excise Tax (including in recent years the GST) and U.I. Contributions. Finally, we also consider the Deficit series without the U.I account.

In what follows, forecast errors are defined to be the realization of the series minus its estimate all divided by the realization two periods before. Errors are thus taken to be errors in growth-rate estimates rather than in nominal dollars. This procedure makes good economic sense and permits us as well to avoiding statistical problems associated with non-stationary series. A two-period rate of growth is chosen to reflect the fact that the level attained the previous period is not known with precision when the forecast is made. The Deficit series is defined in the same way but relative to previous total revenues. The U.I. accounts are handled in levels. The forecast errors, so defined, are depicted in Figures 4a to 41, with the U.I. accounts given in billions of dollars.

As can be seen from Figures 4a, 4h, 4i and 41, the Income Security, Corporate Tax, Excise Tax and Total Revenue forecast error series all seem to take mostly negative values whereby estimates overstate the realization. Such an error can be viewed more positively regarding expenditures than revenues. Series with mostly positive forecast errors include Transfers to Government, U.I. Benefits and the overall Deficit. The other series display a more balanced mixture of positive and negative errors. It should also be noted that some relative forecast errors are as high as $25 \%$ and that large relative errors are not uncommon on the revenue side of the budget. Deficit errors relative to revenue range from modest values during the late 1980s to a $13 \%$ underestimate in 1984 and 10\% in fiscal year 1992. Whereas in 1984 the sizeable error resulted from an unfortunate combination of underestimation regarding Programme Expenditures and overestimation of Income and Corporate Tax revenue, 
the problem in 1992 can be traced entirely to the revenue side where all the revenue series were significantly overestimated.

\section{Results}

In this section tests for unbiasedness, absence of serial correlation, and efficiency will be applied in turn to the budgetary forecast data introduced in the previous Section; in each case, the nonparametric results will be contrasted with results obtained by the more traditional regression-based approach.

To begin, the results for parametric and nonparametric tests of bias and serial correlation are presented in Tables 2 and 3 . With regard to forecast bias on the expenditure side, whereas the regression results indicate that Income Security, Transfers to Government and Debt Service (at the 10\% significance level) are biased, the Wilcoxon tests suggest that the forecast errors in these cases are not symmetric while the median tests, which are robust against asymmetric disturbances, find evidence of bias only in the case of Income Security forecasts. On the Revenue side, the two methodologies concur in finding that Corporate Tax forecasts are biased, but where the traditional regression approach would suggest biased Excise Tax, Total Revenue and Deficit forecasts, the nonparametric results suggest that errors are asymmetric for these series.

Both the sign and regression approaches find evidence of first-order correlation among Income Security forecast errors, as with Transfers to Government on the expenditure side. The nonparametric sign test suggests similar inefficiencies in Income Tax, Corporate Tax and Total Revenue forecasts, results which are only corroborated for Income tax by the parametric results. Both approaches find little evidence of second-order correlation among forecast errors in either the expenditure or revenue side.

To test the external consistency of the forecasts, we used the annual (growth) rates for five standard macroeconomic variables: nominal GDP, real GDP, unemployment, CPI and the three-month T-Bill rate published by Statistics Canada in the spring as the first estimate of the variable for the preceding calendar year. These figures can be assumed to be in the Department of Finance's information set when the fiscal year forecasts are determined in March. The standard parametric procedure to test for forecast efficiency relative to a macroeconomic variable is to regress the forecast error on a constant and several lags of the variable, and to reject the null

hypothesis of efficiency if the F-test that the slope coefficients are all zero is significant. In what follows, we take three lags of the variable. 
It should be recalled from the previous section that in applying the nonparametric efficiency procedures the macroeconomic variables need to be centred around 0 for the tests to have any power. Here we have centered all the series by taking the distance of first differences from a cumulative moving average of first differences beginning in 1965 as defined in (9). Plots of the five macroeconomic series considered in this study along with their centered versions used in the calculation of the nonparametric statistics used in efficiency tests are given in Figures 5 a to $5 \mathrm{e}$. The centering approach given by (9) appears to be effective.

We test eleven of the twelve series for external consistency against the information contained in three lags of each of the macroeconomic variables considered in turn. The Corporate Tax series is omitted on the grounds of bias. In applying the nonparametric procedures, we considering only the sign test as reliable in the case of the Income Security, Transfers to Government, Total Revenue and Deficit series, since the Wilcoxon tests previously applied to these series have found evidence that forecast errors are biased. Nonparametric statistics defined by (5) are calculated for $\mathrm{k}=1,2$ and 3; here we reject the null of efficiency if the smallest p-value among the three tests is less than $\alpha / 3$. Parametric and nonparametric results are presented in Tables 4 and 5 .

On the expenditure side, several contrasts between the nonparametric and parametric results are noteworthy. According to the regression-based approach, Programme Spending appears to be inefficiently forecasted with respect to three of the five macroeconomic series considered; these results are not corroborated by the nonparametric findings. It should be recalled that this is exactly the testing environment where the F-statistic may be found to reject too often, as illustrated by the simulations of Mankiw and Shapiro (1986). On the other hand, the regression-based approach does not suggest as strongly as the sign test that there exists some relationship between the Income Security forecast errors and the information contained in past movements of the Unemployment Rate. Similarly, the Wilcoxon test suggests that there may be some exploitable relationship between forecast errors associated with U.I. Benefits and nominal GDP.

The results differ to some extent as well on the revenue side. The F-statistic is significant in four of the five cases involving the Deficit series; in none of these situations does the sign test reveal any evidence of inefficient forecasting. By contrast, the signed-rank procedures are significant in two cases in the analysis of U.I. Payments, and in both cases the F-test does not reject the null of efficient forecasts. Both nonparametric and parametric procedures suggest inefficiency in the case of Income Tax forecasts relative to information contained in the Unemployment Rate. 
The rejection of the null of efficiency, according to which there is significant correlation between forecast errors and past information, must be carefully interpreted. Such a result simply suggests an avenue whereby forecasts could possibly be improved. In this context, it strikes us that the reliability of the nonparametric results is critical in that unnecessary revisions of current forecasting procedures will tend to be avoided. Of course, it may turn out that the costs of isolating an economic relation which could exploited in the forecasting process is prohibitive and that current forecasting practice can not be improved in the direction suggested by the test result. We wish to emphasize that, as indicated in this empirical study, the nonparametric approach does exhibit power in tests of efficiency and may indicate useful directions for research towards the improvement of forecast performance.

\section{Conclusions}

The expenditure and revenue forecasts provided each year by the Department of Finance to the Federal Government are an important part of the budgetary process which itself figures largely in the public perception of overall government competence, particularly in the fall when the extent of the past year's forecast errors is made public. Notwithstanding the significance of this annual process, there has been little statistical analysis of the actual fiscal forecasts with perhaps the unfortunate consequence that the forecasts may be viewed more as strategic positions rather than intelligent guides to the future.

This paper provides a statistical analysis of the forecasts of significant number of components of the Federal budget. We found that for such a comprehensive analysis it is difficult to extend the analysis prior to 1976 and that the sample available for statistical analysis is of necessity limited. In response, we have described a nonparametric methodology based on signs and signed ranks for evaluating the bias, and internal and external efficiency of forecasts. This approach is more appropriate than the standard regression-based procedures used in this context for two reasons. In contrast to the usual tests the nonparametric tests are reliable in a wider number of circumstances and display comparable or superior power. These points are systematically illustrated in a series of simulation exercises for an appropriately sized sample. It is evident in particular that parametric procedures are unreliable in the presence of asymmetric disturbances and are dominated in power by the sign and signed rank tests.

Applied to the forecasts of the different components of the budget considered in this paper, the nonp arametric found strong evidence of bias only in forecasts of the Corporate Tax revenue series. There is evidence that forecast errors are asym- 
metrically distributed in several of the series. The nonparametric approach finds little evidence that forecast errors are correlated and some evidence (generally in a different direction that the parametric tests would indicate) that the forecasts are inefficient with respect to some macroeconomic information. All in all, we conclude that there is little reason to be concerned with the forecast performance of the Department of Finance, at least from the perspective of these measures of forecast adequacy. To be sure, we could be more assertive if the results were based on a longer sample. But there is even less confidence to be had from a regression analysis. 


\section{BIBLIOGRAPHY}

Campbe11, Bryan and Jean-Marie Dufour, 1991, "Over-rejections in rational expectations models: a nonparametric approach to the Mankiw-Shapiro problem", Economics Letters 35, 285-90.

Campbel1, Bryan and Jean-Marie Dufour, 1994, "Nonparametric orthogonality and random walk tests", Review of Economics and Statistics, forthcoming.

Campbell, Bryan and Eric Ghysels, 1994, "Federal budget projections: A nonparametric assessment of bias and efficiency", Review of Economics and Statistics, forthcoming.

Canadian Budget Documents, selected years.

Canadian Public Accounts, selected years.

Cassidy, Glenn, Mark S. Kamlet, and Daniel S. Nagin, 1989, "An empirical examination of bias in revenue forecasts by state governments", International Journal of Forecasting 5, 321-331.

David, Jean-François and Eric Ghysels, 1989, "Y a-t-il des bias systématiques dans les annonces budgétaires et pourquoi ?", Canadian Public Policy 15, 313-321.

Davidson, Russell and James G. MacKinnon, 1994, "Graphical methods for investigating the size and power of tests", Queen's University manuscript.

Dufour, Jean-Marie, 1981, "Rank tests for serial dependence", Journal of Time Series Analysis 2, 117-128.

Dufour, Jean-Marie and Marc Hallin, 1991, "Nonuniform bounds for nonparametric t-tests", Econometric Theory 7, 253-263.

Feenberg, Daniel R., William Gentry, David Gilroy and Harvey S. Rosen, 1989, "Testing the rationality of state revenue forecasts", The Review of Economics and Statistics 71, 300-308.

Friedman, Benjamin, 1980, "Survey evidence on the 'rationality' of interest rate expectations", Journal of Monetary Economics 6, 453-465.

Gentry, William M., 1989, "Do state revenue forecasters utilize available information?", National Tax Journal 42, 429-439.

Hettmansperger, Thomas P., 1984, Statistical inference based on ranks, New York, Wiley.

Kamlet, Mark S., David C. Mowery and Tsai-Tsu Su, 1987, "Whom do you trust? An analysis of executive and congressional economic forecasts", Journal of Policy Analysis and Management 6, 365-384. 
Lehmann, Eric L., 1975, Nonparametrics: statistical methods based on ranks, Oakland, Holden Day.

Mankiw, N. Gregory and Matthew D. Shapiro, 1986, "Do we reject too often? Small sample properties of rational expectation models", Economics Letters 20, 243247.

McNees, Stephen K., 1978, "The 'rationality' of economic forecasts, American", Economic Review 68, 301-305.

Pesaran, M. Hashem, 1987, The limits to rational expectations, Oxford, Basil Blackwell.

Plesko, George A., 1988, "The accuracy of government forecasts and budget projections", National Tax Journal 41, 483-501.

Pratt, John W. and Jean D. Gibbons, 1981, Concepts of nonparametric theory, New York, Springer-Verlag.

Shkurti, William J. and Darrell Winefordner, 1989, "The politics of state revenue forecasting in Ohio, 1984-1987: a case study and research implications", International Journal of Forecasting 5, 361-371.

Wilcoxon, Frank S., S.K. Katti and Roberta Wilcox, 1970, "Critical values and probability levels for the Wilcoxon rank sum test and the Wilcoxon signed rank test", in: H.L. Harter and D.B. Owen, eds., Selected tables in mathematical statistics, Vol. I, Chicago, Markham. 